Available online at GSC Online Press Directory

GSC Biological and Pharmaceutical Sciences

e-ISSN: 2581-3250, CODEN (USA): GBPSC2

Journal homepage: https://www.gsconlinepress.com/journals/gscbps

(RESEARCH ARTICLE)

\title{
Assessment of antioxidant potentials of functional parts of medicinal plant Uatropa multifida)
}

\author{
Tugbobo Oladimeji $\mathrm{S}{ }^{1, *}$, Oladipo Oluwatosin $\mathrm{O}^{1}$, Olaleye Abike $\mathrm{C}{ }^{1}$, Olaoye Ayonposi $\mathrm{B}{ }^{1}$ and Muraina \\ Taoreed $\mathrm{A}^{2}$ \\ ${ }^{1}$ Department of Science Technology, Federal Polytechnic, Ado-Ekiti, Nigeria. \\ 2 Department of Science Laboratory Technology, Federal Polytechnic, Ede, Osun State, Nigeria.
}

Publication history: Received on 11 April 2020; revised on 24 April 2020; accepted on 28 April 2020

Article DOI: https://doi.org/10.30574/gscbps.2020.11.1.0100

\begin{abstract}
The present research was conducted to evaluate antioxidant properties and phenolic potentials of leaf and flower parts of a medicinal plant (Jatropa multifida). Extracts were prepared from the leaf and flower of the plants with aqueous and methanolic solvents system at $5.0 \%$ concentration. Total phenolic contents of plant extracts was determined by Folin-Ciocalteu method while free radical scavenging ability of leaf and flower plant extracts was assessed using 2,2diphenyl-2-pricrylhydrazyl [DPPH]. Results revealed significantly $(\mathrm{P}<0.05)$ high antioxidant potentials obtained from flower extract which was comparatively higher than that obtained from leaf extract. Highest DPPH inhibition (74\%) was exhibited by methanolic flower extract of Jatropa multifida plant, while the least (66.9\%) DPPH inhibition was demonstrated by aqueous leaf extract. Besides, Jatropa multifida methanolic flower extract contained highest amount (18.0 $\mathrm{mg}$ of catechol $\mathrm{g}^{-1}$ ) of phenols while the lowest amount $\left(8.0 \mathrm{mg}\right.$ of catechol $\mathrm{g}^{-1}$ ) was obtained from aqueous leaf extract of the plant. Results from this investigation suggest that high radical scavenging potentials of this medicinal plant may be attributed to the hydrogen donating ability of phenolics, while organic solvent has higher extractable properties.
\end{abstract}

Keywords: Jatropa multifida; Dipheny; Picryl hydrazy; Antioxidant potentia; Folin-Ciocalteu method

\section{Introduction}

Myriad of studies on phytomedicines have reported that phenolic compounds protect against oxidative stress [1]. Some of these medicinal plants have been investigated for their antioxidative properties and used for treatment of various diseases [2]. Most of the bioactive metabolites from these plants especially flavonoids demonstrated potent antioxidant activity in vitro and in vivo [3]. Many synthetic antioxidants and metal chelator components have also exhibited toxic or mutagenic effect coupled with suppression of body immunity which have shifted attention towards naturally occuring antioxidants [4]. Jatropa multifida is grown specifically for its essential oils in its leaves and flowers where thymol, eugenol, citral, geraniol and linalool have been extracted [5]. Medicinal plants play pivotal role in the health care of ancient and modern cultures, Indians and Chinese system of medicine depend solely on plant based drugs to treat various human ailments since they contain different components of therapeutic value [6].

Besides, plant based drugs remain very important source of therapeutic agents due to availability, relatively cheaper cost as well as non-toxic nature compared to unorthodox medicine [7]. Most medicinal plants contain antioxidant compounds that protect the cells against the damaging effects of reactive oxygen species such as superoxide anions, hydroxyl radicals and hydrogen peroxide [8]. These radicals are are generated in human body via aerobic respiration or rather from exogenous sources and thus play crucial roles in the development of various ailments such as arthritis,

\footnotetext{
${ }^{*}$ Corresponding author: Tugbobo Oladimeji S
} 
asthma, cardiovascular disorders, neurodegenerative and parkinson diseases. However, phenolic compounds from medicinal plants possess strong antioxidant activity and may help protect the cells against oxidative assault caused by free radicals [9].

Hence, the present study was aimed to assess the untapped antioxidant potential of functional parts of Jatropa multifida medicinal plant.

\section{Material and methods}

\subsection{Collection of Plant Sample}

Fresh leaves and flowers of Jatropa multifida plant were fetched from a reserved virgin forest neear Ikere-Ekiti township, Ekiti State, Nigeria. The plant was authenticated at the herbarium centre of Department of Agricultural Technology, Federal Polytechnic, Ado-Ekiti.

\subsection{Preparation of Plant Extracts}

The aqueous extract was prepared by extracting $150 \mathrm{~g}$ of powdered sample in cold sterile distilled water, aggitated with mechanical shaker, and filtered via buchner funnel with No 1 whatman's filter paper, frozen at $-40^{\circ} \mathrm{C}$ and dried with freeze dryer for $72 \mathrm{hrs}$ and percentage yield of $11.33 \%$ was obtained [10]. $120 \mathrm{~g}$ each of powdered samples was extracted with $(70 \%)$ methanol. The mixture was decanted and filtered with No 1 Whatman's filter paper which measured up to $600 \mathrm{mls}$ and was evaporated to dryness to give $9.96 \%$ yield.

\subsection{DPPH Radical Scavenging Assay}

$10 \mu$ l of plant extract (leaf and flower) was added to $100 \mu \mathrm{l}$ of DPPH solution in a microtitre plate. The reaction mixture was incubated at $25^{\circ} \mathrm{C}$ for $5 \mathrm{mins}$ and was left in the dark for $30 \mathrm{mins}$ after which the absorbance was read at $520 \mathrm{~nm}$. DPPH with corresponding solvents without plant extract served as control while methanol with corresponding plant extracts served as blank and was calculated as......

$$
\% \text { Inhibition of DPPH }=\frac{\text { Control }_{\text {Absorbance }}-\text { Test }_{\text {Absorbance }}}{\text { Control }_{\text {Absorbance }}} \times 100
$$

The free radical scavenging ability of leaf and flower extracts of Jatropa multifida plant was determined by 2, 2-diphenyl2-picryl-hydrazyl (DPPH) using method described by [11]. DPPH is a protonated radical with maximum absorption at $517 \mathrm{~nm}$ that decreases with the scavenging of the proton radicals by plant extracts. It is a commercially available stable free radical, purple in colour where the antioxidant molecules in the extracts react with DPPH when incubated and thus convert it into di-phenyl hydrazine, which is yellow in colour. The degree of decolouration of purple to yellow was measured at $520 \mathrm{~nm}$ which is a measure of scavenging potential of plant extracts.

\subsection{Determination of Total Phenols}

The total phenolic content of the Jatropa multifida extracts was determined with [12] method. A reaction mixture of $(\mathrm{v} / \mathrm{v})$ Folin-Ciocalteu reagent and $(\mathrm{w} / \mathrm{v})$ sodium carbonate was added to the extracts and the mixture was vortexed and incubated at $400 \mathrm{C}$ for $30 \mathrm{~min}$ after which the absorbance was measured at $765 \mathrm{~nm}$. Phenols react with phosphomolybidic acid in Folin-ciocalteau reagent in alkaline medium to produce blue colored complex which is estimated colorimetrically.

\subsection{Statistical analysis}

Samples were analyzed in triplicate and the results were presented as Mean \pm S.D. 


\section{Results and discussion}

Table 1 Inhibitory potential of leaf and flower aqueous extracts against DPPH radicals

\begin{tabular}{lll}
\hline Exract conc. $(\mathbf{m g} / \mathbf{m l})$ & \% Inhibition (leaf) & \% Inhibition (flower) \\
\hline Basal & - & - \\
Control & - & - \\
10 & 22.41 & 40.51 \\
20 & 32.46 & 41.32 \\
40 & 46.06 & 61.82 \\
80 & 62.51 & 70.10 \\
160 & 66.91 & 72.82 \\
\hline
\end{tabular}

Table 2 Inhibitory potential of leaf and flower methanolic exrracts against DPPH radicals

\begin{tabular}{lcc}
\hline Exract conc. $(\mathbf{m g} / \mathbf{m l})$ & \% Inhibition (leaf) & \% Inhibition (flower) \\
\hline Basal & - & - \\
Control & - & - \\
10 & 25.00 & 37.11 \\
20 & 38.91 & 37.25 \\
40 & 52.65 & 57.80 \\
80 & 63.92 & 59.20 \\
160 & 67.07 & 74.10 \\
\hline
\end{tabular}

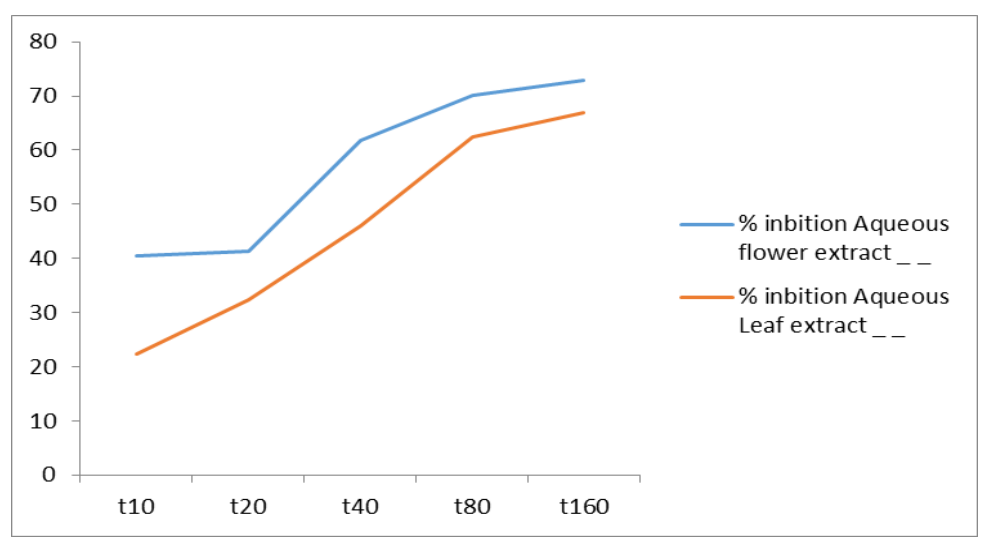

Figure 1 Inhibitory potential of leaf and flower aqueous extracts of Jtropa multifida against DPPH radicals 


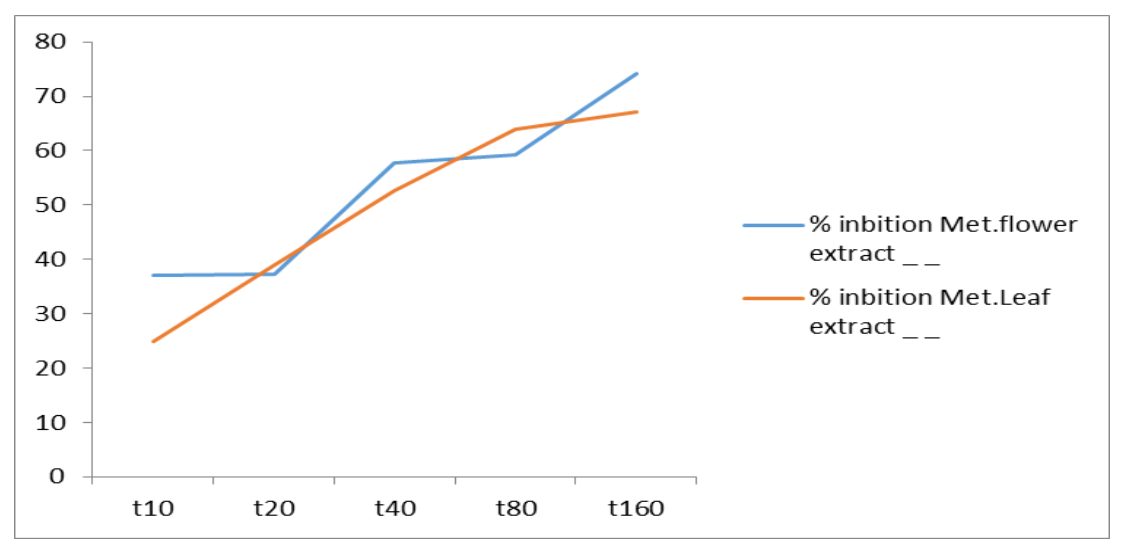

Figure 2 Inhibitory potential of leaf and flower methanolic extracts of Jatropa multifida against DPPH radicals

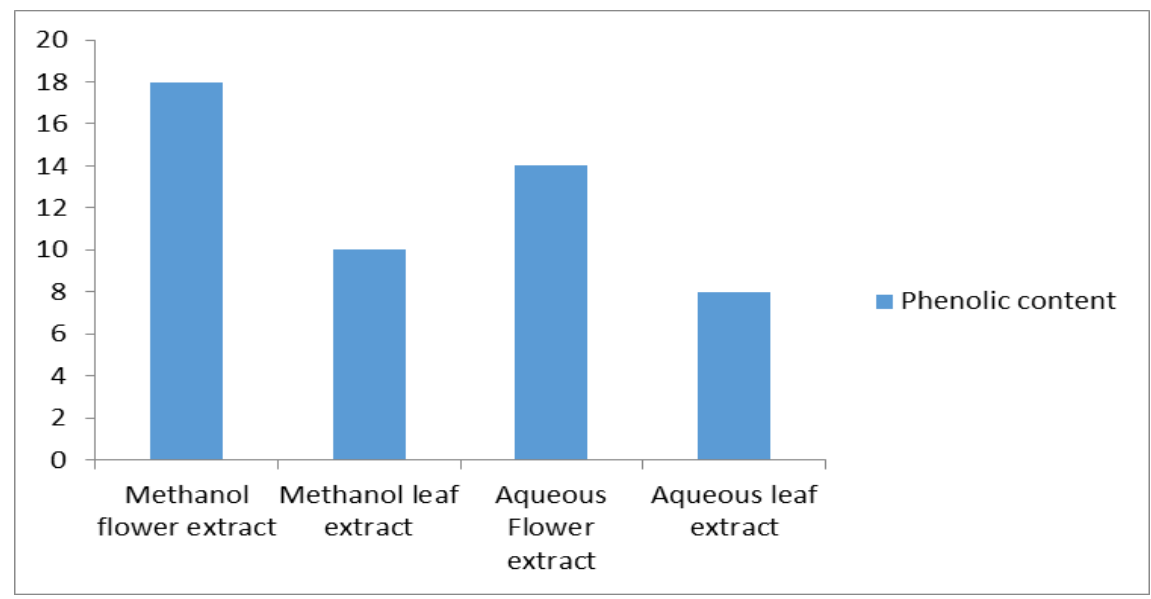

Figure 3 Total phenolic content of aqueous and methanolic extracts of Jatropa multifida leaf and flower

\section{Discussion}

Free radicals are constantly generated resulting in extensive damage to tissues and macromolecules leading to development of various diseases. Medicinal plants are employed as alternative therapy to mitigate the oxidative stress related diseases [13]. Results from this study showed that DPPH scavenging ability of the two parts of Jatropa multifida plant screened in aqueous and methanolic solvent system significantly $(\mathrm{P}<0.05)$ demonstrated strong DPPH inhibition. The flower extracts demonstrated higher DPPH inhibition (74\% and $72.8 \%)$ in methanol and aqueous solvent system respectively when compared to leaf extract with (67.1\% and 66.9\%) obtained from methanol and aqueous solvent system respectively.The high antioxidant capacity of the plant extracts may be attributed to the hydrogen donating ability of its inherent phenols and flavonoids [14]). DPPH is a stable free radical in aqueous and organic medium usually used as a substrate to evaluate the antioxidative activity of antioxidant [15]. It accepts an electron or hydrogen radical to become a stable diamagnetic molecule. Phenolics are pharmacological active component of plant which are capable of neutralizing free radicals, chelating metal catalysts and as well inhibiting activity of oxidizing enzymes in biological system [16]. Hence, the higher antioxidant potential demonstrated by Jatropa multifida flower extract suggests the flower part a better antioxidant riched part of the plant and more suitable for medicinal therapy for treating oxidative stress related diseases. Besides, antioxidant activity of plant often associate with its inherent phenolic compounds as plant phenols constitute its major group of primary antioxidants [17]. Figure 3 shows the total phenolic content of Jatropa multifida plant extracts. The flower extract of the plant possessed higher higher phenolic content than the leaf extract. This further suggests a good correlation between phenolic content and antioxidant activity of the plant which could possibly react with reactive oxygen species (ROS) and thus, inhibit lipid peroxidation that gives rise to oxidative stress [18]. 


\section{Conclusion}

It can be inferred from the data obtained in (Tables 1 and 2) above that flower part of Jatropa multifida plant possesses higher antioxidant potentials which are of greater medicinal values than the leaf part even though both are highly functional.

\section{Compliance with ethical standards}

\section{Acknowledgments}

The authors appreciate everyone that contributed to the success of this research work.

\section{Disclosure of conflict of interest}

No conflict of interest.

\section{References}

[1] Miron DM, Crestani RM, Schetinger MV and Morsch B. (2005). Effect of herbicide clomazone, quinclorac and metsulfuron-methyl on acetylcholinesterase activity in silver catfish. Ecotoxicol. Saf, 61, 398-403.

[2] Weisburger JH. (1999). Mechanism of action of antioxidants as exemplified in vegetables, tomatoes and teas. Food Chem. Toxicol, 37(9-10), 943-948.

[3] Usoh IF, Akpan EJ, Etim EO and Farombi EO. (2005). Antioxidant action of dried flower extract of Habiscus sabdariffa.. L on sodium arsenite induced oxidative stress in rats. Pakistan journal of Nutrition, 4, 135-141.

[4] Fejes SA, Blazovics A, Lugasi E, Lemberkovics G and Kery A. (2000). In vitro antioxidant activity of Anthriscus cerefolium (Hoffin) extracts. J. of Ethnopharmacol, 69, 259-265.

[5] Sulistiarini D, Oyen LPA and Nguyen XD. (1999). Extraction methods of essential oils of Ocimum gratissimum in South-East Asia. Prosen Foundation, Bogor, Indonesia, 140-142.

[6] WHO. (1993). Research guildlines for evaluating safety and efficacy of herbal medicines. Manila World Health organization regional office for western pacific, Switzerland.

[7] Aghor AG and Ngogang YJ. (2005). Toxicity ofherbal preparations. Cam. J.Ethnobotany, 101, 23-28.

[8] Halliwell B and Gutteridge JMC. (1990). Roles of free radicals and catalytic metal ions in human diseases. Enzymol, 186, 18-85.

[9] Kahkonen MP, Hopia AI, Vuorela HJ and Heinonen M. (1999). Antioxidant activity of plant extracts containing phenolic compounds. J. Agric. Food Chem, 47, 3954-3962.

[10] Berln A and Schaller KH. (2008). Modified standard of plant extraction (CCS). Plant Physiol, 25, 665-671.

[11] Gyamfi MA, Yonamine M and Aniya Y. (1999). Free radical scavenging action of herbs from Ghana; Thonningia sanguine on experimentally induced liver injuries. General Pharmacology, 32, 661-667.

[12] Singleton VL, Orthofor R and Lamuela RM. (1999). Analysis of total phenols and other oxidation substratesantioxidants by Folin-Ciocalteu reagent. Methods in Enzymology, 229, 152-178.

[13] Roja G and Rao PS. (2000). Anticancer compounds from tissue culture of medicinal plants. J. Herbs-spices Medicinal Plants, 7, 71-102.

[14] Shimanda K, Fajukawa K, Yahara K and Nakamura T. (1992). Antioxidative properties of xanthan on the autoxidation of soyabean oil in cyclodextrin emulsion. J. Agric. Food Chem., 40(6), 945-948.

[15] Duh PD, Tu YY and Yen GC. (1999). Antioxidant activity of aqueous extract of harn jyur (Chrysanthemum morifolium). Lebensmittel-Wissenschaft and Technologie, 32, 269-277.

[16] Milliauskas G, Venskutonis PR and Van-Beek TA. (2004). Screening of radical scavenging activity of some medicinal and aromatic plant extracts. Food Chem, 85, 231-237.

[17] Hatano T, Edamatsu R, Mori A, Fujita Y and Yasuhara E. (2009). Effect of tannins and related polyphenols on superoxide anions and 1, 1, diphenyl-2-picryl-hydrazyl. Chem. Pharm. Bull, 37, 2016-2023. 
Tugbobo et al. / GSC Biological and Pharmaceutical Sciences, 2020, 11(01), 191-196

[18] Hussain SR, Cillard J and Cillard P. (2007). Hydroxyl radical scavenging activity of flavonoids. Phytochemistry, 26, 2489-2491.

\section{How to cite this article}

Tugbobo OS, Oladipo 00, Olaleye AC, Olaoye AB and Muraina TA. (2020). Assessment of antioxidant potentials of functional parts of medicinal plant (Jatropa multifida). GSC Biological and Pharmaceutical Sciences, 11(1), 191-196. 